\title{
Editorial
}

\section{Remote Sensing and Geospatial Technologies in Public Health}

\author{
Fazlay S. Faruque \\ Department of Preventive Medicine, John D. Bower School of Population Health, University of Mississippi \\ Medical Center, 2500 North State Street, Jackson, MS 39216-4505, USA; ffaruque@umc.edu
}

Received: 11 July 2018; Accepted: 20 July 2018; Published: 30 July 2018

The utilization of remote sensing and geospatial technologies has been instrumental in advancing our understanding of environmental factors affecting human health and well-being. Extreme weather and related phenomena appear to be rising in frequency and intensity which pose growing health risks to human populations. Earth-observing technologies and data are important elements of a comprehensive and multi-scaled public health response at both the micro and macro levels which can identify immediate and long-term impacts. Remote sensing and geospatial technologies have been successfully implemented for more than 50 years; they have examined the role of environmental factors in air-borne, vector-borne, soil-borne, and water-borne diseases. With the availability of new data and advanced technologies, more robust public health measures are being implemented to improve our health and well-being.

Through its regular and special issue publications, the ISPRS International Journal of Geo-Information (IJGI) has been active in providing an advanced forum for the science and technology of geographic information. The idea of a special issue on "Remote Sensing and Geospatial Technologies in Public Health" emerged from the 2nd Symposium on Advances in Geospatial Technologies for Health, which was organized by the ISPRS Working Group on Health in Arlington, Virginia, USA during 24-30 August 2013 [1]. The goals of that symposium were to bridge the geospatial science, Earth science, and health science communities as well as to explore interdisciplinary collaborations to improve our overall health and well-being. This symposium was attended by representatives from international organizations, government agencies, and academia who were actively engaged in advancing different aspects of Remote Sensing and geospatial technologies to benefit public health.

On the basis of the themes of this symposium, a call for papers for this special issue was announced. Submitted manuscripts went through multiple reviews by experts in each field. After intense evaluation, out of 26 submissions, 15 papers were accepted, which are the contents of this book. These papers cover a wide range of health-related issues, including air pollutions, vector-borne diseases, water quality, demographic factors and scale factors, along with emerging analytical techniques. Below are the summaries of the papers.

In "CALPUFF and CAFOs: Air Pollution Modeling and Environmental Justice Analysis in the North Carolina Hog Industry", Yelena Ogneva-Himmelberger and her colleagues address air pollution issues related to Concentrated Animal Feeding Operations (CAFOs) [2]. Here, they demonstrate the uses of meteorological and CAFO data in developing an air pollution dispersion model to estimate ammonia concentrations; they use their estimated ammonia concentrations to evaluate disproportionate exposure of children, elderly, whites, and minorities to this pollutant. They have found that their modelled ammonia concentration is comparable to other established methods. Hence, they feel comfortable to recommend their air pollution dispersion models for environmental justice studies to assess the impacts of the CAFOs and to address concerns regarding the health and quality of life of vulnerable populations. 
The Public Health Agency of Canada (PHAC) predicts that, by the year 2020, 80\% of Canadians will live in Lyme endemic areas. In the paper, "Analyzing the Correlation between Deer Habitat and the Component of the Risk for Lyme Disease in Eastern Ontario, Canada: A GIS-Based Approach", Chen et al. share their experience of developing a geospatial deer habitat suitability model for Eastern Ontario, Canada [3]. The authors expect their model will assist in the development of management strategies to prevent Lyme from becoming a threat to public health in Canada.

Geospatial technology has played a significant global role in the reduction of malaria. In their article, "Geospatial Technology: A Tool to Aid in the Elimination of Malaria in Bangladesh" Kirk et al. evaluate the success in malaria reduction in Bangladesh by effective utilization of geospatial technologies at various levels [4].

To make environmental health-related investigations useful in a clinical environment, it is necessary to incorporate personal level exposure to pollution [5]. In the article, "Examining Personal Air Pollution Exposure, Intake, and Health Danger Zone Using Time Geography and 3D Geovisualization", Yongmei Lu and Tianfang Fang from Texas State University examine personal exposure to air pollution and pollutant intake and define personal health danger zones by expanding traditional time geography and accounting for individual level space-time behavior [6]. Although this study focuses only on ozone, the authors believe that their 3D time-geography approach can be extended to other pollutants for evaluating personal health risks.

Many countries, including the U.S., make huge investments to gather and disseminate geospatial resources that are freely available for public use. However, researchers often cannot take full advantage of these resources due to a lack of basic information. James Acker and his colleagues diligently bring required information about the NASA Giovanni Data System and its potential use to the geospatial public health research community [7]. Since 2003, the Giovanni system has been providing access to a wide variety of NASA remote sensing data and other Earth science data sets, allowing researchers to apply it to a broad range of research topics. In this article, "Use of the NASA Giovanni Data System for Geospatial Public Health Research: Example of Weather-Influenza Connection", the authors describe the public health-related datasets in Giovanni, and inform how to access and utilize those resources. They also demonstrate how Giovanni resources can be used to study the relationship between influenza and meteorological parameters as well as to predict influenza activity.

In the paper, "Mapping Entomological Dengue Risk Levels in Martinique Using High-Resolution Remote-Sensing Environmental Data", Machault et al. discuss the development of entomological risk levels of dengue virus transmission in Martinique, French Antilles through the use of high spatial resolution remote-sensing environmental data along with field entomological and meteorological data [8]. In this paper, they demonstrate the use of the high resolution Geoeye-1 image to extract landscape elements which surrogate societal or biological information related to the life cycle of Aedes vectors.

Use of Remote Sensing data and techniques is not uncommon in water quality monitoring for large water bodies. However, this approach has limitations in smaller areas, such as small lakes. In "Improving Inland Water Quality Monitoring through Remote Sensing Techniques", Igor Ogashawara and Max Moreno-Madriñán document their proposed algorithm, which is specifically designed for monitoring the water quality of small lakes [9].

Although the impact of Modifiable Areal Unit Problem (MAUP) is well known, certain Census geographic unit is often used as the de facto data scale for health geography studies without considering other options. Different geographic scales may result in different results, which can bias public health-related decisions. Lee et al., in their article, "Impacts of Scale on Geographic Analysis of Health Data: An Example of Obesity Prevalence", demonstrate the differences in results from studying the prevalence of obesity using Census Tract and Block Group level data [10].

The location of disease clusters is often a matter of great interest among public health professionals and policymakers. However, the techniques of cluster identification can be quite diverse, resulting in varied results. Mahmoud Torabi and Katie Galloway from the University of Manitoba demonstrate 
five different cluster detection procedures to study geographic variation in the incidence of Chronic Obstructive Pulmonary Disease (COPD) in Manitoba, Canada [11]. In their paper, "Geographical Variation of Incidence of Chronic Obstructive Pulmonary Disease in Manitoba, Canada", Torabi and Galloway discuss the methods, advantages and disadvantages, and the results of the various procedures, which provides a good reference for studying regional cluster analysis for other disease incidences.

With the availability of large amounts of multidimensional data, new techniques are emerging which apply these data to a wide range of applications, including those of health. In their article, "Holistics 3.0 for Health", Lary et al. present a holistic system suitable for complex health studies; this system combines multiple big datasets and multivariate computational techniques, also incorporating new geospatial techniques [12].

Haley Cleckner and Thomas Allen from East Carolina University apply a dasymetric mapping technique to map spatial patterns of vulnerable populations and to characterize potential exposure to mosquito vectors of West Nile Virus across the Chesapeake region of Virginia [13]. In their article, "Dasymetric Mapping and Spatial Modeling of Mosquito Vector Exposure, Chesapeake, Virginia, USA", they quantify mosquito vector abundance, which in combination with a population vulnerability index, they demonstrate an evaluative technique which examines the exposure of human populations to mosquitoes.

In the paper, "Modeling Properties of Influenza-Like Illness Peak Events with Crossing Theory", Wang and his colleagues from the University of Florida, Gainesville propose a methodology to redefine the "peak event" for influenza-like illness (ILI) [14]. As illustrated in this paper, their proposed "peak event" can aid public health professionals to improve the surveillance of influenza and to implement efficient intervention strategies.

In the article, "Correlating Remote Sensing Data with the Abundance of Pupae of the Dengue Virus Mosquito Vector, Aedes aegypti, in Central Mexico", Moreno-Madriñán et al. discuss the successful use of Remote Sensing products to correlate the abundance of the dengue virus mosquito vector, Ae. aegypti, with nighttime land surface temperature [15]. The authors note that, in their study area of central Mexico, the elevation and meteorological conditions significantly vary, but the socio-economic conditions remain relatively uniform, which simplifies the analysis. They demonstrate how their approach of substituting ground meteorological data by remote sensing products can be successfully implemented to predict the abundance of $A$ e. aegypti, the primary mosquito vector of dengue virus. This approach can be replicated in other regions where variables are less complicated, similar to the original study region of Central Mexico.

In their paper, "Canadian Forest Fires and the Effects of Long-Range Transboundary Air Pollution on Hospitalizations among the Elderly", George Le and his colleagues evaluate the transboundary movement of the forest fire-induced $\mathrm{PM}_{2.5}$, which originated in Canada, and its impact on the increase of respiratory and cardiovascular hospital admissions of vulnerable population in the U.S. [16]. Lightning strikes often ignite forest fires, which can contribute to serious air pollution. The authors study the short-term increases in $\mathrm{PM}_{2.5}$ concentrations resulting from forest fires in the province of Quebec, Canada and their impact on respiratory and cardiovascular hospital admissions for the elderly across the east coast of the U.S., as far south as Washington D.C.

In their paper, "Nexus of Health and Development: Modelling Crude Birth Rate and Maternal Mortality Ratio Using Nighttime Satellite Images", Koel Roychowdhury and Simon Jones combine development indicators, health indicators, and nighttime satellite images to propose models for predicting health determinants and development determinants [17].

Although the bridge between the broad areas of health and geospatial technology is not yet well established, there has been tremendous progress in the overarching disciplines as well as in their sub-disciplines. As a member of the geospatial health community, I would urge that we need to keep moving forward and be proactive in making our contributions useful to improve human health and well-being. 
In recent years, there have been unprecedented advancements in the availability of geospatial data, analytical tools, and computational capacity. Access to these resources often tempts us to rush to utilize these resources without giving in-depth thought to the problems and the suitability of the tools for solutions. My hope is that young researchers will pay more attention to the theoretical background of these techniques and their applicability to investigate specific health issues. New generations of geospatial researchers can further advance geospatial technologies to make this world a better place.

I must express my gratitude to the reviewers who contributed their valuable time to provide detailed comments and suggestions to the authors. I also commend the authors for their patience as their manuscripts were going through multiple reviews as well as their diligence in addressing the comments. I also need to mention the professionalism of the IJGI publication team for their support throughout the entire process, from submission to publication, which has been exemplary for an academic publication.

Funding: This research received no external funding.

Conflicts of Interest: The author declares no conflict of interest.

\section{References}

1. ISPRS ICWG III/IVc: Environment and Health. Past Events. 2nd Symposium on Advances in Geospatial Technologies for Health. Available online: http:/ /www2.isprs.org/commissions/comm3/icwg-3-4c/2ndsymposium.html (accessed on 2 July 2018).

2. Ogneva-Himmelberger, Y.; Huang, L.; Xin, H. CALPUFF and CAFOs: Air Pollution Modeling and Environmental Justice Analysis in the North Carolina Hog Industry. ISPRS Int. J. Geo-Inf. 2015, 4, 150-171. [CrossRef]

3. Chen, D.; Wong, H.; Belanger, P.; Moore, K.; Peterson, M.; Cunningham, J. Analyzing the Correlation between Deer Habitat and the Component of the Risk for Lyme Disease in Eastern Ontario, Canada: A GIS-Based Approach. ISPRS Int. J. Geo-Inf. 2015, 4, 105-123. [CrossRef]

4. Kirk, K.; Haq, M.; Alam, M.; Haque, U. Geospatial Technology: A Tool to Aid in the Elimination of Malaria in Bangladesh. ISPRS Int. J. Geo-Inf. 2015, 4, 47-58. [CrossRef]

5. Faruque, F.S.; Finley, R.W. Geographic Medical History: Advances in Geospatial Technology Present New Potentials in Medical Practice. Int. Arch. Photogramm. Remote Sens. Spat. Inf. Sci. 2016. [CrossRef]

6. Lu, Y.; Fang, T. Examining Personal Air Pollution Exposure, Intake, and Health Danger Zone Using Time Geography and 3D Geovisualization. ISPRS Int. J. Geo-Inf. 2015, 4, 32-46. [CrossRef]

7. Acker, J.; Soebiyanto, R.; Kiang, R.; Kempler, S. Use of the NASA Giovanni Data System for Geospatial Public Health Research: Example of Weather-Influenza Connection. ISPRS Int. J. Geo-Inf. 2014, 3, 1372-1386. [CrossRef]

8. Machault, V.; Yébakima, A.; Etienne, M.; Vignolles, C.; Palany, P.; Tourre, Y.; Guérécheau, M.; Lacaux, J.-P. Mapping Entomological Dengue Risk Levels in Martinique Using High-Resolution Remote-Sensing Environmental Data. ISPRS Int. J. Geo-Inf. 2014, 3, 1352-1371. [CrossRef]

9. Ogashawara, I.; Moreno-Madriñán, M. Improving Inland Water Quality Monitoring through Remote Sensing Techniques. ISPRS Int. J. Geo-Inf. 2014, 3, 1234-1255. [CrossRef]

10. Lee, J.; Alnasrallah, M.; Wong, D.; Beaird, H.; Logue, E. Impacts of Scale on Geographic Analysis of Health Data: An Example of Obesity Prevalence. ISPRS Int. J. Geo-Inf. 2014, 3, 1198-1210. [CrossRef]

11. Torabi, M.; Galloway, K. Geographical Variation of Incidence of Chronic Obstructive Pulmonary Disease in Manitoba, Canada. ISPRS ISPRS Int. J. Geo-Inf. 2014, 3, 1039-1057. [CrossRef]

12. Lary, D.; Woolf, S.; Faruque, F.; LePage, J. Holistics 3.0 for Health. ISPRS Int. J. Geo-Inf. 2014, 3, 1023-1038. [CrossRef]

13. Cleckner, H.; Allen, T. Dasymetric Mapping and Spatial Modeling of Mosquito Vector Exposure, Chesapeake, Virginia, USA. ISPRS Int. J. Geo-Inf. 2014, 3, 891-913. [CrossRef] 
14. Wang, Y.; Waylen, P.; Mao, L. Modeling Properties of Influenza-Like Illness Peak Events with Crossing Theory. ISPRS Int. J. Geo-Inf. 2014, 3, 764-780. [CrossRef]

15. Moreno-Madriñán, M.; Crosson, W.; Eisen, L.; Estes, S.; Estes, M., Jr.; Hayden, M.; Hemmings, S.; Irwin, D.; Lozano-Fuentes, S.; Monaghan, A.; et al. Correlating Remote Sensing Data with the Abundance of Pupae of the Dengue Virus Mosquito Vector, Aedes aegypti, in Central Mexico. ISPRS Int. J. Geo-Inf. 2014, 3, 732-749. [CrossRef]

16. Le, G.; Breysse, P.; McDermott, A.; Eftim, S.; Geyh, A.; Berman, J.; Curriero, F. Canadian Forest Fires and the Effects of Long-Range Transboundary Air Pollution on Hospitalizations among the Elderly. ISPRS Int. J. Geo-Inf. 2014, 3, 713-731. [CrossRef]

17. Roychowdhury, K.; Jones, S. Nexus of Health and Development: Modelling Crude Birth Rate and Maternal Mortality Ratio Using Nighttime Satellite Images. ISPRS Int. J. Geo-Inf. 2014, 3, 693-712. [CrossRef]

2018 by the author. Licensee MDPI, Basel, Switzerland. This article is an open access article distributed under the terms and conditions of the Creative Commons Attribution (CC BY) license (http:/ / creativecommons.org/licenses/by/4.0/). 